\title{
Reclassification of the taxonomic status of SEMIA3007 isolated in Mexico B-11A Mex as Rhizobium leguminosarum bv. viceae by bioinformatic tools
}

\author{
Luciano Takeshi Kishi ${ }^{\dagger}$, Camila Cesário Fernandes ${ }^{\dagger}$, Wellington Pine Omori, João Carlos Campanharo
} and Eliana Gertrudes de Macedo Lemos ${ }^{*}$

\begin{abstract}
Background: Evidence based on genomic sequences is extremely important to confirm the phylogenetic relationships within the Rhizobium group. SEMIA3007 was analyzed within the Mesorhizobium groups to define the underlying causes of taxonomic identification. We previously used biochemical tests and phenotypic taxonomic methods to identify bacteria, which can lead to erroneous classification. An improved understanding of bacterial strains such as the Mesorhizobium genus would increase our knowledge of classification and evolution of these species.

Results: In this study, we sequenced the complete genome of SEMIA3007 and compared it with five other Mesorhizobium and two Rhizobium genomes. The genomes of isolated SEMIA3007 showed several orthologs with M. huakuii, M. erdmanii and M. loti. We identified SEMIA3007 as a Mesorhizobium by comparing the 16S rRNA gene and the complete genome.

Conclusion: Our ortholog, $16 \mathrm{~S}$ rRNA gene and average nucleotide identity values (ANI) analysis all demonstrate SEMIA3007 is not Rhizobium leguminosarum bv. viceae. The results of the phylogenetic analysis clearly show SEMIA3007 is part of the Mesorhizobium group and suggest a reclassification is warranted.
\end{abstract}

Keywords: Genome sequencing, Core genome, Comparative analysis, Ortholog genes, Phylogenetic analysis

\section{Background}

Rhizobia is the collective name of the genera Rhizobium, Sinorhizobium and Mesorhizobium, which are soil and rhizosphere bacteria of agronomic importance because they form nitrogen-fixing symbioses with leguminous plants $[1,2]$. Thus, rhizobia are considered bio-fertilizers and have been used as inoculants for over 120 years. Rhizobial genetic diversity and the plant-bacteria molecular interactions have been well-studied [3]. The growth rate of Mesorhizobium is intermediate between the genera Rhizobium and Bradyrhizobium and is one of

\footnotetext{
* Correspondence: egerle@fcav.unesp.br

${ }^{\dagger}$ Equal contributors

Departamento de Tecnologia, Laboratório de Bioquímica de Microrganismos e Planta - LBMP, UNESP - Universidade Estadual Paulista, Faculdade de Ciências Agrárias e Veterinárias, Via de Acesso Prof. Paulo Donato Castellane s/n, 14884-900 Jaboticabal, SP, Brazil
}

(c) The Author(s). 2016 Open Access This article is distributed under the terms of the Creative Commons Attribution 4.0 International License (http://creativecommons.org/licenses/by/4.0/), which permits unrestricted use, distribution, and reproduction in any medium, provided you give appropriate credit to the original author(s) and the source, provide a link to the Creative Commons license, and indicate if changes were made. The Creative Commons Public Domain Dedication waiver (http://creativecommons.org/publicdomain/zero/1.0/) applies to the data made available in this article, unless otherwise stated. genera consists of 24 species found in Asia, Europe, the Mediterranean region and Africa $[4,5]$.

Jarvins et al. [6] were the first to request the creation of the Mesorhizobium genus and reclassified several genera identified as Rhizobium into Mesorhizobium. The correct phylogenetic identification of a species requires an accurate technical characterization $[7,8]$.

The taxonomy of Mesorhizobium requires the reclassification of species because there is a need for studies to avoid classification problems. Taxonomic information provides access to basic trait information such as physiology, epidemiology and evolutionary history [9]. The correct taxonomic assignment of bacterial genomes is a primary and challenging task [10-13]. 
The partial 16S ribosomal RNA gene (16S rRNA) is a molecular marker widely used in the taxonomy of bacteria. However, this gene has no consensus sequence to correctly classify microorganisms at the species level [14-16]. Thus, DNA-DNA hybridization (DDH) has been used as the gold standard for defining prokaryotic species at the genomic level. DDH is the only taxonomic method that offers a numerical and relatively stable species. Therefore, DDH influences how the current classification system has been constructed [17].

$\mathrm{DDH}$ is an expensive and laborious method that is available in only a few laboratories worldwide, since it requires the hybridization of hundreds of strains and often does not resolve the taxonomic problems. However, it is an important limiting factor for the description of new species, particularly in countries with the greatest biodiversity. Prokaryotic species continue to be a group of strains due to DNA-DNA re-association values greater than $70 \%[14,18]$.

The recent development of sequencing technologies has enabled us to carefully assess microbial communities by generating many nucleotide sequences at lower costs. Next generation sequencing (NGS) technologies have revolutionized the field of microbial ecology and allows researchers to determine the level of diversity more closely using in-depth sequencing. There are various applications using these NGS platforms, which range from single-gene targeted sequencing to whole-genome sequencing and shotgun metagenome sequencing [19]. With the availability of whole genome sequences, the gene content based approaches appear promising in inferring the bacterial taxonomy. The complete genome sequencing of a bacterial genome often reveals a substantial number of unique genes present only in that genome which can be used for its taxonomic classification $[11,12]$.

The recent improved access to various new gene sequences and the definition of prokaryote species has led to doubts regarding the suitability of the DNA-DNA hybridization method [20]. The new proposals include the analysis of several genes or the entire genome. One proposed analysis method is to analyze common genes between two strains and determine the average nucleotide identity values (ANI). An ANI value exceeding $94 \%$ corresponds to $70 \%$ traditional DNA-DNA hybridization [21, 22].

This analysis method also considers genes with ecological functions. Other ANI values suggested replacing $70 \%$ hybridization with $95 \%$ ANI and $69 \%$ conserved DNA. In the protein coding portion of the genome, these values would suggest $85 \%$ conserved genes [23]. The most recent proposals recommend > 95-96\% ANI to delineate species and would replace the traditional $70 \%$ cut off threshold used for DDH sequences [17].
The aim of this study was to evaluate SEMIA3007 isolated in Mexico as B-11A Mex and is classified by phenotypic taxonomic methods such as Rhizobium leguminosarum bv. viceae by different groups of researchers. We used a combination of complete 16S rRNA sequencing and complete genome analysis to reclassify B-11A as Mesorhizobium sp.

\section{Results and discussion}

\section{Bacterial growth curve}

The bacterial growth curve of SEMIA3007 is shown in Fig. 1. SEMIA3007 grew similar to the median strains of Rhizobium, Mesorhizobium and Bradyrhizobium. These findings phenotypically characterize SEMIA3007 as part of the genus Mesorhizobium. This strain was originally isolated in Mexico (B-11A Mex) and classified taxonomically as Rhizobium leguminosarum bv. viceae SEMIA3007 by a combination of phenotypic methods, biochemical tests and partial sequencing of the 16S rRNA gene.

\section{Genome assembly of SEMIA3007 and its features}

The sequencing result shows that strain SEMIA3007 has the following characteristics: one contig of 6,990,002 bp, $\mathrm{G}+\mathrm{C}$ content $63 \%, 6,814$ coding sequences (CDS) and a total of 55 RNAs. In the SEMIA3007 genome, there are two clusters encoding nitrite reductase (nirV and nirK) and four clusters related to denitrification processes that reduce nitrate to nitrogen gas. It is postulated that after host infection this cluster is responsible for allowing Brucella suis to survive low oxygen concentrations because the cells can use nitrogen oxides as final electron acceptors [24, 25]. The presence of this pathway enables SEMIA3007 to use this mechanism of intracellular survival during host infection.

We also found the following other genes were present in the genome of SEMIA3007: nifA, nifS, nifU, IscA-like,

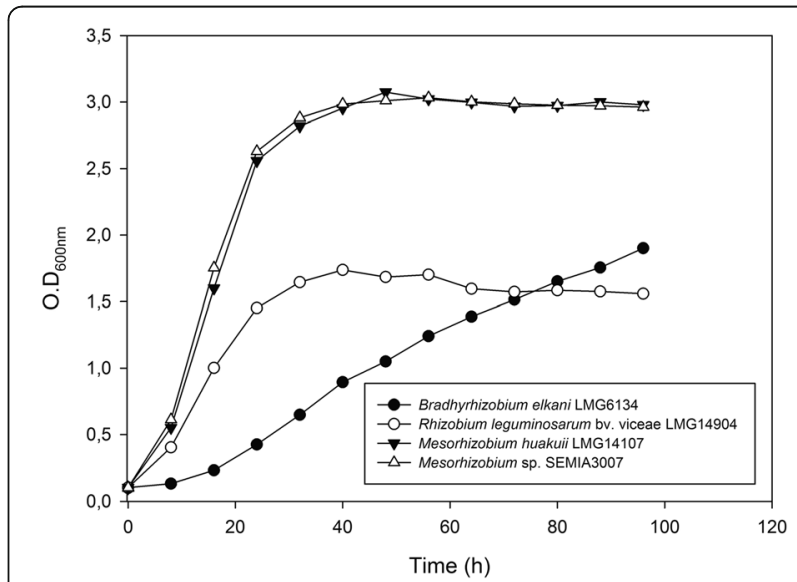

Fig. 1 Bacterial growth curve. Bradyrhizobium elkanii LMG6134, Rhizobium leguminosarum bv. viceae LMG14904, Mesorhizobium huakuii LMG14107 and Mesorhizobium sp. SEMIA3007 strains 
$n i f \mathrm{~B}, \operatorname{frd} \mathrm{N}, n i f \mathrm{X}, n i f \mathrm{X} 2, n i f \mathrm{E}, n i f \mathrm{~N}, n i f \mathrm{Q}, n i f \mathrm{~W}, n i f \mathrm{H}, n i f \mathrm{D}$, nifK, nifZ and nif $\mathrm{T}$. These results suggest mechanisms for denitrification processes. The nif genes function in the transformation of ammonia nitrogen, nitrate, and nitrite ammonification and code for proteins such as nitrate reductase (EC 1.7.99.4), nitrite reductase [NAD(P)H] (EC 1.7.1.4), ferredoxin-nitrite reductase (EC 1.7.7.1) and nitrite reductase (cytochrome; ammoniaforming) (EC 1.7.2.2).

The SEMIA3007 genome also contains a subsystem for assimilation of ammonia and the bacteria can use ammonia assimilated for metabolism of amino acids (glutamate). The system uses glutamate ammonia ligase (EC 6.3.1.2), glutamate synthase (NADPH) (EC 1.4.1.13), glutamate synthase (NADH) (EC 1.4.1.14) and glutamate synthase (ferredoxin) (EC 1.4.7.1).

System secretions of type I, type II, type IV and type VI were identified. These system components are common among rhizobia. The type IV secretion systems are identified in microorganisms associated with plants and are usually composed of Vir proteins [26]. The operon of the type IV SEMIA3007 system features 12 genes encoding the following proteins: VirB1-VirB4, VirB6, VirB8-VirB9, VirB11, VirD4 and VirG. The virB region is responsible for coding key virulence factors in the symbiosis species Mesorhizobium [26, 27]. This operon may assist in inducing acidification of the phagosome in the cells after phagocytosis. The acidification may lead to the segregation of unknown effector molecules and create changes in the host cell endosome that generate a new intracellular compartment in which the attacker can replicate [28]. The secretion systems of types III, IV and VI and the nodulation factors are considered responsible for lead host specificity in Mesorhizobium huakuii [4].

\section{Genome comparisons of SEMIA3007 and Rhizobium}

Our analysis of the similarity between genomes can be used to differentiate microorganisms. We used the genomes of SEMIA3007, Rhizobium leguminosarum bv. viceae (gi 115254414), Rhizobium leguminosarum bv. trifolii (gi 240861949), Mesorhizobium erdmanii (gi 548692182), Mesorhizobium ciceri (gi 317165637), Mesorhizobium huakuii (gi 657121522), Mesorhizobium loti (gi 47118328) and Mesorhizobium opportunistum (gi 336024847) to construct a progressive alignment using the program Mauve. We found there was a high degree of similarity (block synteny and direction) between SEMIA3007 and the Mesorhizobium group and a limited number of blocks collinear between Rhizobium (Fig. 2).

ANI [23] is one method that has replaced the DDH [29], and it is the best in silico parameter representing $\mathrm{DDH}$ that has been experimentally demonstrated $[22,29]$. Our genome comparisons for taxonomic purposes were based on BLAST calculations [30]. An ANI value of $95 \% \pm 0.5 \%$ identity corresponds to $70 \% \mathrm{DDH}$ [23], which is a value often recommended to delimit species when used in conjunction with other criteria, such as phenotypic traits [31].

Richter and Rossello-Mora [17] describe a software tool (JSpecies) designed to easily allow the calculation of ANI based on the BLAST algorithm [30] and the MUMmer ultra-rapid aligning tool [32]. We also calculated the tetranucleotide frequencies, which are alignment-free parameters that have been successfully applied to phylogenetically sort metagenome inserts [33]. Therefore, the 95-96 \% ANI threshold can be readily used as an objective boundary for species circumscription if it is reinforced by high TETRA correlation values [17]. Our results demonstrate that SEMIA3007 is more genetically similar to Mesorhizobium huakuii than Rhizobium (Table 1).

\section{Phylogenetic analysis using 16S rRNA}

The results of sequencing the 16S rRNA gene SEMIA3007 were subjected to a membership analysis taxonomy in RDPII bank. We utilized the classifier tool with a threshold of $95 \%$. The result showed the identity was $100 \%$ Mesorhizobium. Additionally, there was $100 \%$ identity with the $16 \mathrm{~S}$ Ribosomal RNA database using the Blast program (June 2006).

A phylogenetic analysis was performed using data available on the NCBI database to assess whether SEMIA3007 should be identified and cataloged as Rhizobium leguminosarum bv. viceae within Rhizobium or be reclassified as part of the Mesorhizobium group (Additional file 1: Table S1).

The results of the phylogenetic analysis clearly show SEMIA3007 is a member of Mesorhizobium and is separate from the Rhizobium group, which suggests a reclassification of SEMIA3007 is warranted (Fig. 3).

\section{Comparison of gene orthologs}

Previous studies have compared genes to differentiate organisms. We used OrthoMCL clustering to identify "core genes", which are the number of unique and shared orthologs of SEMIA3007 and Mesorhizobium (Fig. 4). A total of 32,604 proteins from SEMIA3007 (6,814 proteins), M. huakuii (5,838 proteins), M. erdmanii (6,491 proteins), M. loti (7,043 proteins) and $M$. opportunistum (6,418 proteins) were evaluated. We used an inflation index of 1.5 to complete genes and identified 3,075 ortholog groups within the five genomes.

The clusters of orthologs in Fig. 4 show there are 3,075 ortholog groups in SEMIA3007 representing $69.5 \%$ of the total CDS in the genome. However, SEMIA3007 and M. huakuii showed 3,951 (79.1 \%) common ortholog groups. We found that SEMIA3007 


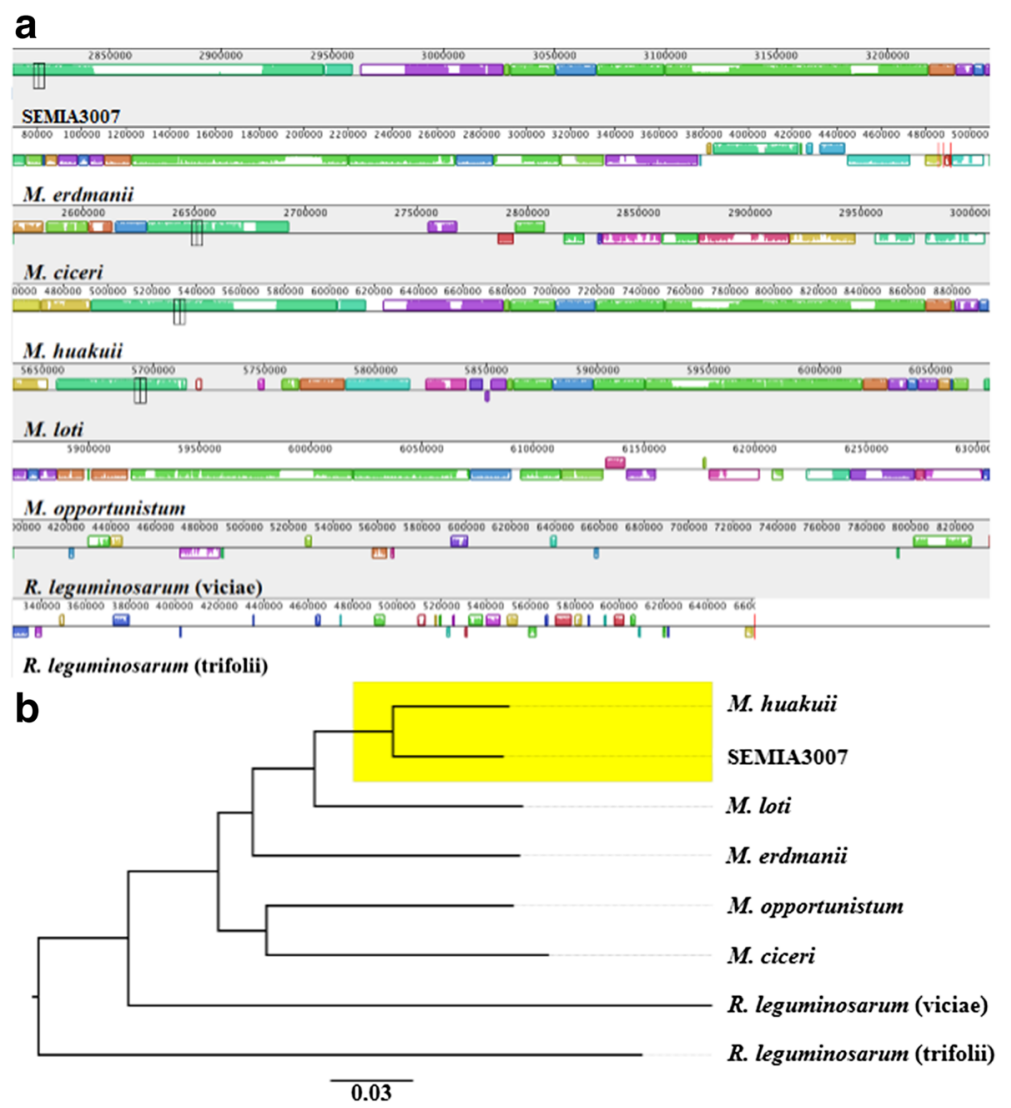

Fig. 2 Genomes comparison between Mesorhizobium and Rhizobium. a A genome alignment of eight genomes using Mauve reveals collinear blocks conserved (LCB) among all genomes. Each chromosome is shown horizontally and homologous blocks in each genome are shown as identically colored regions. $\mathbf{b}$ Similarity between genomes aligned by Mauve program showing the phylogenetic relationships between genomes

and M. erdmanii shared 4,392 (87.9\%) orthologs. There were 4,197 (84 \%) orthologs in common between SEMIA3007 and M. loti. There were also 3,984 (79 \%) orthologs shared between SEMIA3007 and M. opportunistum. Therefore, isolated SEMIA3007 shows a large number of Mesorhizobium gene orthologs. These findings suggest that SEMIA3007 is a Mesorhizobium strain.

Therefore, the results for growth curve of SEMIA3007, comparative analysis of the genome, ANI,

Table 1 Probability of pairwise comparison

\begin{tabular}{lllllll}
\hline & Genome (bp) & \%GC & Gene & \%ANIb & \%ANIm & \%Tetra \\
\hline SEMIA3007 & 6990002 & 62.9 & 7173 & - & - & - \\
M. huakuii & 6364365 & 63.2 & 5838 & 98.45 & 98.94 & 99.97 \\
M. loti & 7036071 & 62.7 & 7043 & 93.46 & 94.64 & 99.96 \\
M. opportunistum & 6884444 & 62.9 & 6418 & 87.31 & 89.17 & 99.85 \\
M. ciceri & 6264489 & 62.5 & 6100 & 85.70 & 87.25 & 99.85 \\
M. erdmanii & 7018265 & 62.7 & 6491 & 88.89 & 90.40 & 99.86 \\
R. leg_viciae & 5057142 & 61.1 & 4797 & 70.72 & 83.54 & 95.75 \\
R. leguminosarum & 7418122 & 60.7 & 7293 & 70.27 & 82.79 & 96.01 \\
\hline
\end{tabular}

Nucleotide identity values (ANI) and correlation indexes of their Tetra-nucleotide signatures between SEMIA3007 with Mesorhizobium and Rhizobium gene orthologs and phylogenetic analysis using $16 \mathrm{~S}$ rRNA show that SEMIA3007 is not Rhizobium leguminosarum bv. viceae suggesting its reclassification for Mesorhizobium group [10-13].

\section{Conclusions}

NGS technologies have proven their utility in genomic and metagenomics areas since their earliest application appeared in 2006. Identifying each individual sequence is important in microbial community analysis because the taxonomic information provides access to basic trait information such as physiology, epidemiology and evolutionary history. The taxonomic information also permits indirect inference of their ecological roles in a given environment [19].

Whole-genome sequencing has proven to be valuable and critical for refining the phylogenetic positions and correct taxonomic classification of rhizobial strains $[10,11,34]$. In this study, we sequenced, assembled and annotated the SEMIA3007 genome. We used this genome sequence to examine the phylogenetic relationship between Mesorhizobium and Rhizobium genus. SEMIA3007 was classified by phenotypic 


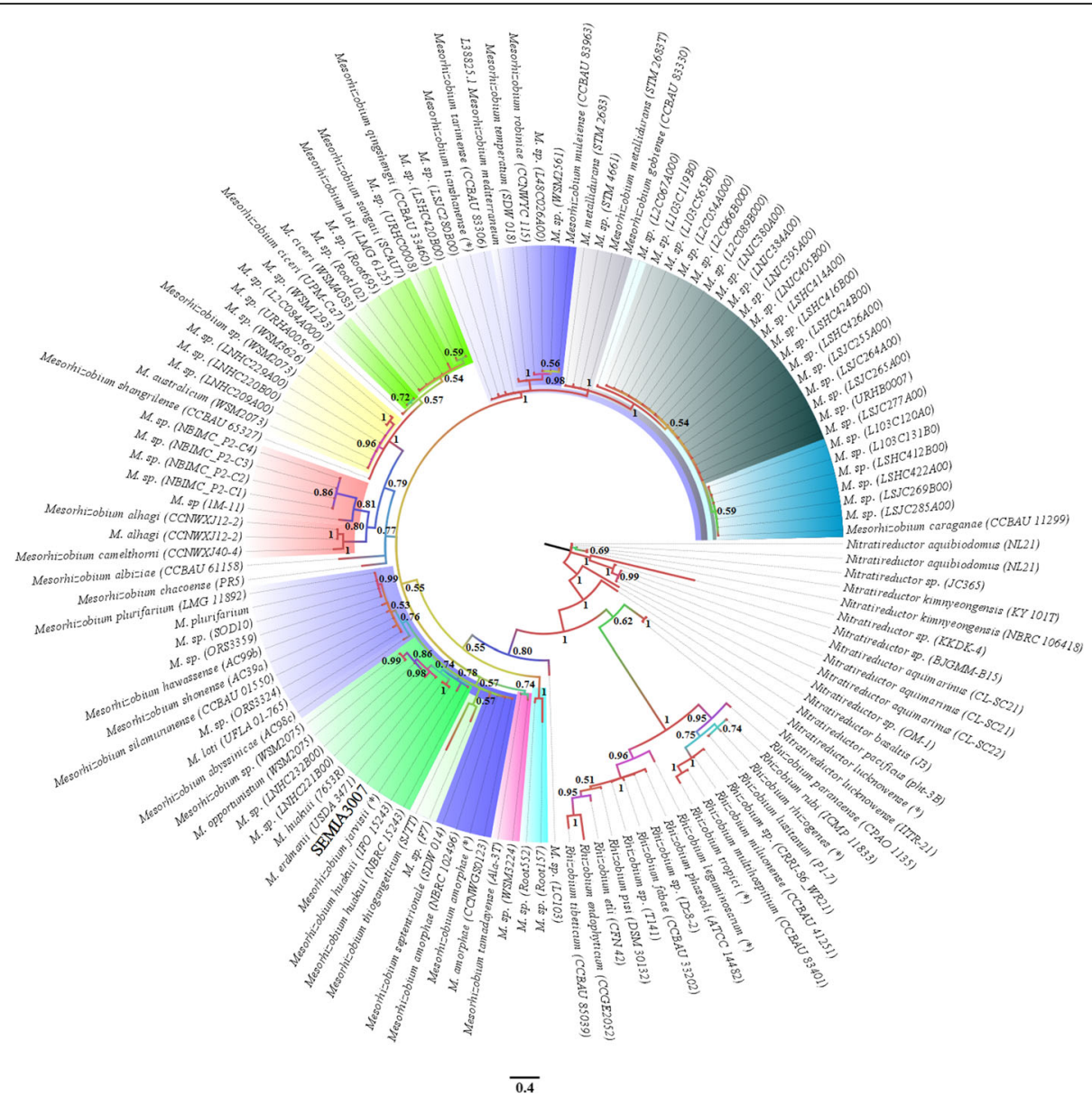

Fig. 3 Phylogenetic tree showing the taxonomic position of SEMIA3007 strain between groups of Mesorhizobium and Rhizobium. Genetic differences between bacteria of $0.4 \%$. The numbers in the branches show the probability calculated by MrBayes with the colors

taxonomic methods and biochemical tests as Rhizobium leguminosarum bv. viceae. However, our results strongly suggest that SEMIA3007 belongs to the Mesorhizobium genus. The placement of SEMIA3007 in a Mesorhizobium genus is supported by our analysis of ANI, ortholog genes and phylogenetic analysis.

We can see a high degree of similarity and block synteny and direction between SEMIA3007 and the Mesorhizobium group. Our results demonstrated there were a limited number of blocks collinear between Rhizobium. Additionally, the ANI based on a pairwise genome comparison of all shared ortholog protein coding genes is $98 \%$ with Mesorhizobium huakuii. Our phylogenetic analysis demonstrated that SEMIA3007 is not part of the Rhizobium genus, and the ortholog genes revealed sufficient ability to identify SEMIA3007 as Mesorhizobium.

The concepts of orthology originated from the field of molecular systematics [35] and have recently been applied to functional characterizations and classifications on the scale of whole-genome comparisons [36-38]. In comparative genomics, the clustering of orthologous genes provides a framework for integrating information from multiple genomes by highlighting the divergence and conservation of gene families and biological processes.

The identification of orthologous groups in prokaryotic genomes has permitted cross-referencing of genes from multiple species and has facilitated genome annotation, protein family classification, studies on bacterial evolution and the identification of strains. The ultimate goal of taxonomy is to construct a classification that is operative and predictive for any discipline in microbiology. The classification is also essentially stable for old and new strain such as Rhizobia and the collective names of the genera Rhizobium, Sinorhizobium, Mesorhizobium.

\section{Methods}

\section{Bacterial growth curve}

The strains of Bradyrhizobium elkanii LMG6134, Rhizobium leguminosarum bv. viceae LMG14904, Mesorhizobium huakuii LMG14107 and Mesorhizobium sp. SEMIA3007 were cultured for $96 \mathrm{~h}$ with shaking 


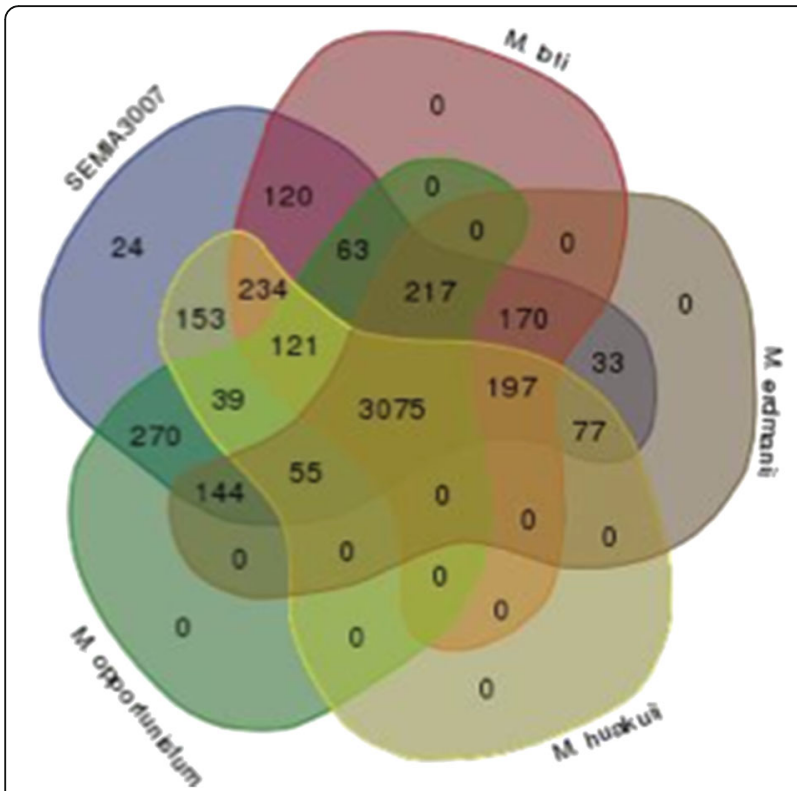

Fig. 4 Venn diagram showing core genome analyses of Mesorhizobium strains. The number of protein-coding gene ortholog sharing among five Mesorhizobium. SEMIA3007; M. huakuii (CP006581.1); M. loti (NC_002678.2); M. opportunistum (NC_015675.1); M. erdmanii (NZ_AXAE01000048.1)

(150 rpm) at $30{ }^{\circ} \mathrm{C}$ in TY medium [39] in triplicate. To obtain the bacterial growth curve, the OD reading was collected every $8 \mathrm{~h}$.

\section{Bacterial strain and DNA preparation}

SEMIA3007 was cultured for $48 \mathrm{~h}$ at $28{ }^{\circ} \mathrm{C}$ with $145 \mathrm{rpm}$ shaking in TY medium [39]. The SEMIA3007 cells were harvested by centrifugation, and the total DNA was prepared using a Wizard ${ }^{\odot}$ Genomic DNA Purification Kit (Promega).

\section{Sequencing and annotation of the genome}

The de novo sequencing of the SEMIA3007 genome used a combined strategy involving Illumina - HiscanSQ. The libraries were constructed using a TruSeq ${ }^{\circ}$ DNA Sample Prep kit and Nextera Mate Pair Sample Preparation kit (Illumina ${ }^{\circledR}$ ). The cluster formation of library templates was performed with the TruSeq PE Cluster kit v3 (Illumina ${ }^{\circ}$ ) and the Illumina cBot workstation using conditions recommended by the manufacturer. Paired end 100 base pair (2x100bp) sequencing by synthesis was performed with TruSeq SBS kit v3 (Illumina) on an Illumina HiscanSQ using protocols defined by the manufacturer. The base call conversion to sequence reads was performed using CASAVA 1.8.3 (Illumina ${ }^{\circledR}$ ). As a result, paired-end and mate pair fastq files were trimmed using Scythe 0.991 (https://github.com/vsbuffalo/scythe), Cutadapt 1.7.1 [40] and the quality of data was filtered by Prinseq program [41] with Phred $\geq 20$. The sequence assembly was performed using the Spades 3.6.1 program [42]. The prediction of ORFs and annotation were performed using the Rast system [43].

\section{Genome comparisons and average nucleotide identity (ANI)}

For comparing the genome of SEMIA3007 to others genomes we compute an alignment of the six genomes, we used the Progressive Mauve algorithm [44]. An alignment of the four Mesorhizobium and Rhizobium genomes was constructed using the default mauveAligner parameters. The resulting LCBs were inspected using the Mauve alignment viewer, and the minimum LCB weight was adjusted to eliminate LCBs consisting of only repetitive elements (LCB Weight 600).

Reference genomes for comparison purposes were retrieved from the GenBank database (http://www.ncbi.nlm. nih.gov/genbank/). Sequences were uploaded into the JSpecies software package (http://www.imedea.uib.es/ jspecies) to perform pairwise genome calculations of the average nucleotide identity (ANI) [17, 23] and support the proposed cut-off level of $95 \%$ as a species delineation threshold [22].

\section{Ortholog analysis}

The ortholog groups in multiple genomes can be useful for annotation and revealing the patterns of phylogenetic proteins from different strains. The groups also provide insights into the evolutionary conservation and diverse cellular functions in different species.

Four coding sequences (CDS) from genomes/drafts of Mesorhizobium loti, Mesorhizobium huakuii, Mesorhizobium erdmanii and Mesorhizobium sp. were extracted from GenBank files (Additional file 1: Table S1), representing four species (five with SEMIA3007 CDS). The pan and core genome analysis was conducted by determining shared (homologous) and species-specific protein-coding genes using OrthoMCL [36] with e-value cutoff $1 \times 10^{-20}$, protein percent identity $\geq 50 \%$ and MCL inflation of 1.5. OrthoMCL computes families of homologous genes for pan and core genome analyses. The families in which two or more genomes participate were used to determine numbers plotted. OrthoMCL was run with blast e-value cut-off of $1 e-5$ and an inflation parameter of 1.5. The table with orthologs was used to plot Venn diagrams (http://bioinformatics.psb. ugent.be/webtools/Venn/) [36].

\section{S rRNA gene sequencing}

The amplification of the 16S rRNA gene of the SEMIA3007 was performed with FD1 and RD1 primers [45]. The PCR reaction mixture consisted of $30 \mathrm{ng}$ of DNA, 7.5 pmol of each primer, $0.2 \mathrm{mM}$ of dNTPs, $1.5 \mathrm{mM}$ of $\mathrm{MgCl}_{2}$, Buffer $1 \mathrm{X}$ and $2.5 \mathrm{U}$ Taq DNA 
polymerase (Ludwig Biotec). A thermocycler model PTC$100{ }^{\mathrm{TM}}$ Programmable Thermal Controller (M) Research, Inc.) was used with a thermal profile of $96{ }^{\circ} \mathrm{C}$ for $2 \mathrm{~min}$, 40 cycles of $96{ }^{\circ} \mathrm{C}$ for $30 \mathrm{~s}, 53^{\circ} \mathrm{C}$ for $1 \mathrm{~min}$ and $60{ }^{\circ} \mathrm{C}$ for $4 \mathrm{~min}$. After the PCR reaction, the products were purified with a Wizard ${ }^{\circ}$ SV Gel and PCR Clean-Up System (Promega). The amplicon was sequenced with $1 \mu \mathrm{l}$ of BigDye Terminator v3.1, buffer $0.75 \mathrm{X}$ (Tris- $\mathrm{HCl} 200 \mathrm{mM}$, $\mathrm{pH} 9.0$ and $\mathrm{MgCl} 25 \mathrm{mM}$ ), 10 pmoles of primer FD1, $50 \mathrm{ng}$ of DNA and sterile Milli-Q distilled water (10 $\mu \mathrm{L}$ q.s.p). Sequencing was performed on Sequencer ABI PRISM 3130xl DNA Analyzer (Applied Biosystems) following the manufacturer's instructions.

\section{Downloading the sequences $16 \mathrm{~S}$ rRNA in GenBank}

The National Center for Biotechnology Information (NCBI) was used to search the genome for species Mesorhizobium (March 15, 2016). All complete gene sequences for $16 S$ rRNA (16S ribosomal RNA) were downloaded from GenBank (Additional file 1: Table S1) [46].

\section{Phylogenetic analysis of 16S rRNA gene}

The 16S rRNA gene set were aligned using the MAFFT v7.215 program [47]. The search for the best nucleotide substitution matrix was performed with the Phangorn package [48] in $\mathrm{R}$ [49] and the feature modelTest. The construction of a phylogenetic tree was performed with the Mrbayes v3.2.2 program [50] using the matrix replacement General Time Reversible (GTR) with gamma variation (G) and invariable sites (I) with 10.000.000 generations. The best evolutionary model was chosen based on Akaike information criterion with correction (AICc).

\section{Nucleotide sequence accession number}

The data sets results of this article are available in the NCBI BioProject SRR3703040.

\section{Additional file}

Additional file 1: Table S1. Complete genomes and drafts. (XLSX 18 kb)

\begin{abstract}
Abbreviations
$16 S$ rRNA: 165 ribosomal RNA gene; AICc: Akaike information criterion with correction; ANI: Average nucleotide identity values; CDS: Coding sequences; DDH: DNA-DNA hybridization; DNA: Deoxyribonucleic acid; GTR: General time reversible; LCB: Collinear blocks conserved; LCB: Locally collinear blocks; NAD(P)H: Nitrite reductase; NADH: Glutamate synthase; NADPH: Glutamate synthase; NCBI: National Center for Biotechnology Information; NGS: Next generation sequencing; OD: Optical density; ORF: Open read frame; PCR: Polymerase chain reaction; TY: Triptone, yeast medium
\end{abstract}

\section{Acknowledgements}

We gratefully acknowledge Universidade Estadual Paulista - UNESP, the Programa de Pós Graduação em Microbiologia Agropecuária, UNESP, Jaboticabal, São Paulo State, Brazil. We also thank FAPESP (grants: 2009/ 539842; 2014/14234-6) and CNPq.
Funding

This work was supported by FAPESP (grants: 2009/539842; 2014/14234-6) and CNPq.

\section{Availability of data and materials}

The data sets results of this article are available in the NCBI BioProject SRR3703040

http://www.ncbi.nlm.nih.gov/sra/?term=SRR3703040

The data sets results from phylogenetic tree of this article are avaiable in: http://purl.org/phylo/treebase/phylows/study/TB2:S20064

You can cite this URL in your manuscript. It will become the permanent and resolvable resource locator after your submission has been approved and the data are made public.

http://purl.org/phylo/treebase/phylows/study/TB2:S20064?x-accesscode $=c 3247 \mathrm{bbe7382039c0d043d51a87de8e8 \& format=html}$

You can copy and send this URL to you journal editor to provide reviewers with limited, read-only access to your data, even if your submission has not yet been approved and the data are not yet public.

\section{Authors' contributions}

Conceived and designed the experiments: LTK CCF EGML. Performed the experiments: LTK CCF JCC EML. Analyzed the data: LTK WPO. Contributed reagents/materials/analysis tools: EGML. Wrote the paper: CCF LTK. All authors read and approved the final manuscript.

\section{Competing interests}

The authors declare that they have no competing interests.

Consent for publication

All authors are aware of the publication.

Ethics approval and consent to participate

All authors are aware of the publication.

Received: 29 July 2016 Accepted: 28 October 2016

Published online: 04 November 2016

References

1. Kaneko T, Nakamura Y, Sato S, Asamizu E, Kato T, Sasamoto S, et al. Complete genome structure of the nitrogen-fixing symbiotic bacterium Mesorhizobium loti. DNA Res. Int J Rapid Publ Rep Genes Genomes. 2000:7:331-8.

2. Velázquez E, Peix A, Zurdo-Piñiro $J$, Palomo JL, Mateos PF, Rivas R, et al. The coexistence of symbiosis and pathogenicity-determining genes in Rhizobium rhizogenes strains enables them to induce nodules and tumors or hairy roots in plants. Mol Plant Microbe Interact. 2005;18:1325-32.

3. Graham PH, Sadowsky MJ, Keyser HH, Barnet YM, Bradley RS, Cooper JE, et al. Proposed minimal standards for the description of new genera and species of root- and stem-nodulating bacteria. Int J Syst Bacteriol. 1991:41:582-7.

4. Wang S, Hao B, Li J, Gu H, Peng J, Xie F, et al. Whole-genome sequencing of Mesorhizobium huakuii 7653R provides molecular insights into host specificity and symbiosis island dynamics. BMC Genomics. 2014;15:440.

5. Degefu T, Wolde-meskel E, Liu B, Cleenwerck I, Willems A, Frostegard A. Mesorhizobium shonense sp. nov., Mesorhizobium hawassense sp. nov. and Mesorhizobium abyssinicae sp. nov., isolated from root nodules of different agroforestry legume trees. Int J Syst Evol Microbiol. 2013;63:1746-53.

6. Jarvis BDW, Van Berkum P, Chen WX, Nour SM, Fernandez MP, Cleyet-Marel JC, et al. Transfer of rhizobium loti, rhizobium huakuii, rhizobium ciceri, rhizobium mediterraneum, and rhizobium tianshanense to mesorhizobium gen. nov. Int J Syst Bacteriol. 1997;47:895-8.

7. Mousavi SA, Willems A, Nesme X, de Lajudie P, Lindström K. Revised phylogeny of rhizobiaceae: proposal of the delineation of pararhizobium gen. nov., and 13 new species combinations. Syst Appl Microbiol. 2015;38:84-90.

8. Mousavi SA, Österman J, Wahlberg N, Nesme X, Lavire C, Vial L, et al. Phylogeny of the Rhizobium-Allorhizobium-Agrobacterium clade supports the delineation of Neorhizobium gen. nov. Syst Appl Microbiol. 2014;37:208-15.

9. Martínez-Hidalgo P, Martínez-Molina E, Mateos PF, Velázquez E, Peix Á, Flores-Félix JD, et al. Revision of the taxonomic status of type strains of 
Mesorhizobium loti and reclassification of strain USDA 3471 T as the type strain of Mesorhizobium erdmanii sp. nov. and ATCC 33669 T as the type strain of Mesorhizobium jarvisii sp. nov. Int. J. Syst. Evol. Microbiol. 2015;65:1703-8.

10. Ormeño-Orrillo E, Servín-Garcidueñas $L E$, Rogel MA, González V, Peralta $H$, Mora J, et al. Taxonomy of rhizobia and agrobacteria from the Rhizobiaceae family in light of genomics. Syst Appl Microbiol. 2015;38:287-91.

11. Gupta A, Sharma VK. Using the taxon-specific genes for the taxonomic classification of bacterial genomes. BMC Genomics [Internet]. 2015 [cited 2016 Oct 4];16. Available from: http://www.biomedcentral.com/1471-2164/ 16/396. Accessed 5 Oct 2016

12. Teng JLL, Tang Y, Huang Y, Guo F-B, Wei W, Chen JHK, et al. Phylogenomic Analyses and Reclassification of Species within the Genus Tsukamurella: Insights to Species Definition in the Post-genomic Era. Front. Microbiol. [Internet]. 2016 [cited 2016 Oct 4];7. Available from: http://journalffrontiersin. org/Article/10.3389/fmicb.2016.01137/abstract. Accessed 5 Oct 2016

13. Mcllroy SJ, Lapidus A, Thomsen TR, Han J, Haynes M, Lobos E, et al. High quality draft genome sequence of Meganema perideroedes str. Gr1T and a proposal for its reclassification to the family Meganemaceae fam. nov. Stand. Genomic Sci. [Internet]. 2015 [cited 2016 Oct 4];10. Available from: http://www.standardsingenomics.com/content/10/1/23. Accessed 5 Oct 2016.

14. Vandamme P, Pot B, Gillis M, de Vos P, Kersters K, Swings J. Polyphasic taxonomy, a consensus approach to bacterial systematics. Microbiol Rev. 1996;60:407-38.

15. Kim B-Y, Weon H-Y, Cousin S, Yoo S-H, Kwon S-W, Go S-J, et al. Flavobacterium daejeonense sp. nov. and Flavobacterium suncheonense sp. nov., isolated from greenhouse soils in Korea. Int I Syst Evol Microbiol. 2006;56:1645-9.

16. Menna P, Hungria M, Barcellos FG, Bangel EV, Hess PN, MartínezRomero E. Molecular phylogeny based on the 16S rRNA gene of elite rhizobial strains used in Brazilian commercial inoculants. Syst Appl Microbiol. 2006;29:315-32

17. Richter M, Rossello-Mora R. Shifting the genomic gold standard for the prokaryotic species definition. Proc Natl Acad Sci. 2009;106:19126-31.

18. Coenye T, Gevers D, Van de Peer Y, Vandamme P, Swings J. Towards a prokaryotic genomic taxonomy. FEMS Microbiol Rev. 2005;29:147-67.

19. Kim M, Lee K-H, Yoon S-W, Kim B-S, Chun J, Yi H. Analytical tools and databases for metagenomics in the next-generation sequencing era. Genomics Inform. 2013;11:102

20. Achtman M, Wagner M. Microbial diversity and the genetic nature of microbial species. Nat. Rev. Microbiol. [Internet]. 2008 [cited 2016 Jun 22]; Available from: http://www.nature.com/nrmicro/journal/v6/n6/abs/ nrmicro1872.html. Accessed 5 Oct 2016.

21. Konstantinidis KT, Tiedje JM. Genomic insights that advance the species definition for prokaryotes. Proc Natl Acad Sci. 2005;102:2567-72.

22. Konstantinidis KT, Tiedje JM. Trends between gene content and genome size in prokaryotic species with larger genomes. Proc Natl Acad Sci U S A. 2004:101:3160-5.

23. Goris J, Klappenbach JA, Vandamme P, Coenye T, Konstantinidis KT, Tiedje JM. DNA-DNA hybridization values and their relationship to whole-genome sequence similarities. Int J Syst Evol Microbiol. 2007;57:81-91.

24. Kohler S, Foulongne V, Ouahrani-Bettache S, Bourg G, Teyssier J, Ramuz M, et al. Nonlinear partial differential equations and applications: the analysis of the intramacrophagic virulome of Brucella suis deciphers the environment encountered by the pathogen inside the macrophage host cell. Proc Natl Acad Sci. 2002;99:15711-6

25. Haine V, Dozot M, Dornand J, Letesson J-J, De Bolle X. NnrA is required for full virulence and regulates several brucella melitensis denitrification genes. J Bacteriol. 2006;188:1615-9.

26. Hubber AM, Sullivan JT, Ronson CW. Symbiosis-induced cascade regulation of the Mesorhizobium loti R7A VirB/D4 type IV secretion system. Mol Plant Microbe Interact. 2007;20:255-61.

27. Soto MJ, Sanjuan J, Olivares J. Rhizobia and plant-pathogenic bacteria: common infection weapons. Microbiology. 2006;152:3167-74.

28. Boschiroli ML, Ouahrani-Bettache S, Foulongne V, Michaux-Charachon S, Bourg G, Allardet-Servent A, et al. Type IV secretion and Brucella virulence. Vet Microbiol. 2002:90:341-8.

29. Garrity GM, Trüper HG, Whitman WB, Grimont PAD, Nesme X, Frederiksen $W$, et al. Report of the ad hoc committee for the re-evaluation of the species definition in bacteriology. Int J Syst Evol Microbiol. 2002;52:1043-7.
30. Altschul SF, Gish W, Miller W, Myers EW, Lipman DJ. Basic local alignment search tool. J Mol Biol. 1990;215:403-10.

31. Rosselló-Mora R, Amann R. The species concept for prokaryotes. FEMS Microbiol Rev. 2001;25:39-67.

32. Delcher AL, Kasif S, Fleischmann RD, Peterson J, White O, Salzberg SL. Alignment of whole genomes. Nucleic Acids Res. 1999;27:2369-76.

33. Teeling H, Meyerdierks A, Bauer M, Amann R, Glockner FO. Application of tetranucleotide frequencies for the assignment of genomic fragments. Environ Microbiol. 2004:6:938-47.

34. Schuldes J, Rodriguez Orbegoso M, Schmeisser C, Krishnan HB, Daniel R, Streit WR. Complete genome sequence of the broad-host-range strain sinorhizobium fredii USDA257. J Bacteriol. 2012;194:4483.

35. Fitch WM. Distinguishing homologous from analogous proteins. Syst Zool. 1970;19:99.

36. Li L. OrthoMCL: identification of ortholog groups for eukaryotic genomes. Genome Res. 2003;13:2178-89.

37. Tatusov RL, Koonin EV, Lipman DJ. A genomic perspective on protein families. Science. 1997;278:631-7.

38. Chervitz SA, Aravind L, Sherlock G, Ball CA, Koonin EV, Dwight SS, et al. Comparison of the complete protein sets of worm and yeast: orthology and divergence. Science. 1998;282:2022-8.

39. Beringer JE. R factor transfer in Rhizobium leguminosarum. J Gen Microbiol. 1974;84:188-98

40. Martin M. Cutadapt removes adapter sequences from high-throughput sequencing reads. EMBnet J. 2011;17:10

41. Schmieder R, Edwards R. Quality control and preprocessing of metagenomic datasets. Bioinformatics. 2011;27:863-4.

42. Bankevich A, Nurk S, Antipov D, Gurevich AA, Dvorkin M, Kulikov AS, et al. SPAdes: a new genome assembly algorithm and its applications to single-cell sequencing. J Comput Biol. 2012;19:455-77.

43. Aziz RK, Bartels D, Best AA, DeJongh M, Disz T, Edwards RA, et al. The RAST server: rapid annotations using subsystems technology. BMC Genomics. 2008:9:75

44. Darling ACE. Mauve: multiple alignment of conserved genomic sequence with rearrangements. Genome Res. 2004;14:1394-403.

45. Weisburg WG, Barns SM, Pelletier DA, Lane DJ. 16S ribosomal DNA amplification for phylogenetic study. J Bacteriol. 1991:173:697-703.

46. Laranjo M, Alexandre A, Oliveira S. Legume growth-promoting rhizobia: an overview on the Mesorhizobium genus. Microbiol Res. 2014;169:2-17.

47. Katoh K. MAFFT: a novel method for rapid multiple sequence alignment based on fast Fourier transform. Nucleic Acids Res. 2002;30:3059-66.

48. Schliep KP. phangorn: phylogenetic analysis in R. Bioinformatics. 2011;27:592-3.

49. Ihaka R, Gentleman R. R: A language for data analysis and graphics. J Comput Graph Stat. 1995;5:299-314

50. Ronquist F, Teslenko M, van der Mark P, Ayres DL, Darling A, Hohna S, et al. MrBayes 3.2: efficient bayesian phylogenetic inference and model choice across a large model space. Syst Biol. 2012;61:539-42.

\section{Submit your next manuscript to BioMed Central and we will help you at every step:}

- We accept pre-submission inquiries

- Our selector tool helps you to find the most relevant journal

- We provide round the clock customer support

- Convenient online submission

- Thorough peer review

- Inclusion in PubMed and all major indexing services

- Maximum visibility for your research

Submit your manuscript at www.biomedcentral.com/submit 